\title{
Economia criativa e desenvolvimento: um estudo do Grupo Canção Nova em Cachoeira Paulista/SP
}

\author{
Bruno Nascimento Vieira Da Cunha ${ }^{1}$ \\ Monica Franchi Carniello ${ }^{2}$ \\ Edson Trajano Vieira ${ }^{3}$
}

\begin{abstract}
Resumo
Economia Criativa é um conceito contemporâneo e se apresenta como fonte de geração de atividade econômica na perspectiva do desenvolvimento regional. O artigo visa analisar como surgiu e se organiza a Economia Criativa no Grupo Canção Nova em suas ações, atividades, produtos, serviços e profissionais criativos no município de Cachoeira Paulista/SP. Estabelecida em um ambiente tradicional, pouco urbanizado e não populoso, de marcante presença religiosa histórica, não multicultural e de baixa pluralidade, o Grupo Canção Nova em Cachoeira Paulista representa uma forma diversa ao relatado até então pela literatura. A metodologia contemplou pesquisa documental, coleta de dados qualitativos por meio de entrevistas em profundidade com profissionais criativos do Grupo Canção Nova. Foram considerados também dados de registros documentais de marcas e direitos autorais, e comparados com os dados qualitativos das entrevistas e levantados dados do mapeamento de Economia Criativa no município, realizado pela FIRJAN entre os anos de 2004 a 2015. Os resultados demostram a aproximação do Grupo Canção Nova com o conceito de indústria criativa. A análise demonstrou que houve contribuição para o desenvolvimento nas dimensões econômica e social do município, seja por meio da própria Economia Criativa do Grupo, seja pelo suporte que esta representa às atividades sociais.
\end{abstract}

Palavras-chave: Canção Nova. Cachoeira Paulista. Economia Criativa.

\begin{abstract}
Creative Economy is a contemporary concept and presents itself as a source of generation of economic activity in the perspective of regional development. The article aims to analyze how the Creative Economy emerged and organized in the Canção Nova Group in its actions, activities, products, services and creative professionals in the municipality of Cachoeira Paulista / SP. Established in a traditional, little urbanized and non-populous environment, with a strong historical, non-multicultural and low pluralistic religious presence, the Canção Nova Group in Cachoeira Paulista represents a different form than that reported in the literature. The methodology included documental research, collection of qualitative data through in-depth interviews with creative professionals of the Canção Nova Group. Data were also taken from documentary records of trademarks and copyrights, and compared with the qualitative data of the interviews and data collected from the Creative Economy mapping in the municipality, carried out by FIRJAN between the years 2004 to 2015. The results show the Group's approach New song with the concept of creative industry. The analysis showed that there was a contribution to development in the economic and social dimensions of the city, either through the Group's own Creative Economy or through the support it represents to social activities.
\end{abstract}

Key words: Canção Nova. Cachoeira Paulista. Creative Economy.

\section{Introdução}

O conceito de Economia Criativa tem-se desenvolvido amplamente desde as primeiras publicações acerca deste modo de organização social e econômica. Os trabalhos pioneiros de Howkins (2001) e Florida (2011) trouxeram à tona uma inovadora forma de geração de riqueza, trabalho e renda para cidades, estados e nações. Países como Austrália e Inglaterra logo se apoderaram do conceito e passaram a implementar políticas públicas para fomento da Economia

\footnotetext{
${ }^{1}$ Mestrado em Planejamento e Desenvolvimento Regional. brunocunhacn@gmail.com

2 Doutorado em Comunicação e Semiótica (PUC/SP). Pós-Doutorado em Comunicação (Universidade do Minho-PT). Professora do Programa de Pós-Graduação em Planejamento e Desenvolvimento Regional da Universidade de Taubaté. monicafcarniello@gmail.com.

${ }^{3}$ Doutor em História Econômica. Professor do Programa de Pós-Graduação em Planejamento e Desenvolvimento Regional da Universidade de Taubaté. etrajanov@gmail.com.
} 
Criativa em suas economias, com a promoção de projetos e estratégias nacionais (MIGUEZ, 2007).

Economia Criativa é primeiramente observada no relatório australiano Creative Nation (1994). Três anos após, em 1997, o Reino Unido, em seu Departamento de Cultura, Mídia e Esporte, se determinou a fazer políticas públicas para promover e estabelecer uma força-tarefa de integração das suas Indústrias Criativas (DCMS, 1998). Tal estratégia visou dinamizar e impulsionar a economia do país diante da competição internacional, tendo-se em vista a participação importante da Indústria Criativa no PIB - Produto Interno Bruto. A partir disso, se desenvolveram novos modelos de Economias Criativas, que perpassam o contexto cultural, do capital intelectual, direitos autorais e criatividade e inovação. $O$ modelo atual internacionalmente discutido se baseia no estudo da ONU - Organização das Nações (UNCTAD, 2013).

A atual conjuntura econômica global é, cada vez mais, vista como um período de transição, do paradigma fordista para a sociedade do consumo, da cultura e da criatividade (HARVEY, 1993). Uma transição do modelo econômico do século XX, de predomínio da sociedade com enfoque industrial, para uma economia voltada ao setor de serviços. As redes de informação, em âmbito de conectividade global, dadas as novas tecnologias, têm-se mostrado como fortes influenciadoras da troca de informações e conhecimento.

As cadeias produtivas, consumo, produção e distribuição, começam a se fundir e romper barreiras antes definidas e estruturadas na era industrial. Ainda dentro do processo junta-se a globalização das culturas e das novas ideias criativas em velocidade superior à vista no século passado (VIEIRA; SANTOS; CARNIELLO, 2016).

A Economia Criativa é hoje um tema significativo na busca pelo desenvolvimento regional, uma vez que comporta uma maior integração social, econômica e cultural, do local e do espacial. Sua relevância se deve também ao fato de que potencialmente pode provocar maior desenvolvimento nas dimensões econômico-social, e não somente o crescimento econômico, pelo caráter inclusivo do profissional criativo que favorece o desenvolvimento na dimensão social, uma vez que o talento e o indivíduo se encontram no cerne da produção da Economia Criativa, mas também pela produção de produtos e serviços criativos e não industriais que beneficiam o desenvolvimento sustentável. Segundo Vieira (2009, p. 18), “O desenvolvimento econômico é o crescimento econômico acompanhado pela melhoria do padrão de vida da população e por alterações fundamentais na estrutura da econômica social".

Neto e Menezes (2016) complementam, ao afirmar que a Economia Criativa se diferencia da economia tradicional (indústria, agricultura e comércio), pois tem seu foco no potencial individual ou coletivo para produção de bens e serviços. Os produtos criativos, tangíveis ou intangíveis, produzem uma nova forma de riqueza, uma vez que geram inovação com conteúdo criativo e valor econômico.

Organizações produtivas focadas em Economia Criativa captam ideias, internalizam e externam a criatividade na forma de produtos e serviços, valores, (ideias-forças). Geram novos estilos de vida alternativos, diferente do regime produtivo fordista tradicional (PIRES; ALBAGLI, 2012). Conforme Leitão (2011), os fatores produtivos da Economia Criativa se diferenciam dada 
sua capacidade de reinvenção, multiplicação a partir das ideias, e por não serem baseados em recursos naturais ou escassos. Argumenta ainda que:

Diferentemente da economia tradicional "taylorista", a Economia Criativa se caracteriza pela abundância e não pela escassez, pela sustentabilidade social e não pela exploração de recursos naturais e humanos, pela inclusão produtiva e não pela marginalização de indivíduos e comunidades (LEITÃO, 2011, p.14).

Diante do processo da Economia Criativa, observa-se o Grupo Canção Nova, entidade sem fins lucrativos, filantrópica e religiosa, sediada em Cachoeira Paulista, no Estado de São Paulo. Sua atividade está ligada à religiosidade católica, a singularidade, criatividade e inovação e produção de produtos e serviços criativos. Caracterizada como organização de Economia Criativa, o Grupo não pode ser visto, portanto, como uma indústria tradicional, fordista, com linha de produção e processos de gestão industrial.

Fundada no final dos anos 1970 pelo Padre Jonas Abib, a Canção Nova teve sua origem na cidade de Queluz, no Estado de São Paulo, e tinha como objetivo inicial promover encontros religiosos para jovens católicos. Com o passar dos anos, já na década de 1980, se expande por intermédio de eventos religiosos e de meios de comunicação em massa, Rádio e TV (ABIB, 2012). O modelo de gestão do grupo, portanto, se baseou na estratégia de gestão criativa dentro de diversas áreas da Economia Criativa que foram mapeadas.

Atualmente o Grupo Canção Nova é composto por setores produtivos e gerenciado por profissionais da criatividade, entre os quais: Arquitetura, Publicidade, Design, Artes Cênicas, Música, Expressões Culturais, Editorial, Audiovisual e Tecnologia da Informação Comunicação TIC. Possui ainda atuação em outras áreas, como escola de Ensino Básico, Fundamental, Médio e Superior, produção de água mineral e leite, dentre outros (FUNDAÇÃO JOÃO PAULO II, 2016).

$\mathrm{O}$ artigo visa analisar como surgiu e se organiza a Economia Criativa no Grupo Canção Nova em suas ações, atividades, produtos, serviços e profissionais criativos no município de Cachoeira Paulista/SP. Estabelecida em um ambiente tradicional, pouco urbanizado e não populoso, de marcante presença religiosa histórica, não multicultural e de baixa pluralidade, o Grupo Canção Nova em Cachoeira Paulista representa uma forma diversa ao relatado até então pela literatura.

\section{Referencial teórico}

A literatura acerca da Economia Criativa é bastante prolífica. Diversos autores têm-se destacado no estudo e na delimitação teórica do conceito. Destacam-se os trabalhos pioneiros de Howkins (2001), em Como Ganhar Dinheiro Com Ideias Criativas, que tornou o conceito conhecido e debatido internacionalmente. Florida (2011), em sua obra A Ascensão Da Classe Criativa, que originou o debate da Economia Criativa sobre a classe criativa e sua emergência em cidades cosmopolitas. Também obteve destaque o relatório da UNCTAD (ONU) Creative Economy. No Brasil, a discussão se deu em diversos autores, em especial em Reis (2008), em sua discussão sobre Cidades Criativas, e o mapeamento de Indústria Criativa da FIRJAN (2016) entre os anos de 2003 e 2015, dentre outras obras. 
Economia Criativa está em debate atualmente, mas foi primeiramente discutido por Howkins (2001), que procurou demonstrar a novidade do tema que já existia anteriormente nos anos 1990 em estudos e relatórios na Austrália e no Reino Unido. Para o autor, o conceito pode ser definido como a relação entre a criatividade e a economia, tal como relata: "A criatividade não é algo novo, tampouco a economia, mas a novidade está na natureza e na extensão da relação entre elas e como elas se combinam para criar valor e riquezas extraordinários" (HOWKINS, 2001, p. 12).

Segundo Reis (2011), a criatividade está ligada à Economia Criativa, uma vez que é composta por uma classe criativa, no sentido de que o dinamismo e a pujança econômica se encontram nos conjuntos de empresas e pessoas criativas. Os profissionais criativos se destacam pela singularidade com que trabalham. Ideias não são frutos de insumos tradicionais, como aço, cobre ou derivados de petróleo. A criatividade é a essência de seus produtos finais e emergem de ambientes que proporcionem o novo, o original e o singular.

Segundo Muzzio e Paiva Junior (2014), são os indivíduos criativos que compõem a Economia Criativa e representam uma vantagem competitiva relevante. Mas o que motiva esses indivíduos? Os objetivos e estímulos dos profissionais criativos se dão por causas internas e pessoais, e não somente por contexto político e econômico. Logo, se observa um engajamento maior a partir do momento em que se tem a identificação entre profissional, ambiente e produtos/serviços criativos. Tal engajamento ocorre, dentre outros fatores, por influência do líder criativo, como influenciador dos comportamentos dos profissionais e das equipes criativas (CARVALHAL; MUZZIO, 2015).

Florida (2011) afirma que a criatividade humana desempenha um papel fundamental na economia e na sociedade, e torna-se, cada vez mais, a força motriz dos países, das cidades e regiões, e toma o lugar da industrialização tradicional, baseada em recursos naturais (petróleo, minerais e água). A criatividade tem-se tornado o combustível principal da economia, da sociedade e do trabalho humano. O chamado "ímpeto criativo", definido como ponto de diferenciação de outras espécies, é visto hoje em forma efervescente como nunca visto.

A classe criativa é constituída por novos trabalhadores impulsionados por suas identidades singulares, e cujo combustível é a paixão pela criatividade e inovação. A classe criativa difere consideravelmente da classe trabalhadora industrial tradicional, e é formada, em sua maioria, por indivíduos das artes plásticas e do design, da música e do entretenimento, das engenharias e arquitetura, e, por fim, das ciências e da educação. No tocante à função da classe criativa na economia, é percebida como geradores de novas ideias e conteúdos, tecnologias e serviços (FLORIDA, 2011).

Em torno da classe criativa, o que foi visto nos dados coletados é a presença de uma série de profissionais que estão em volta da criatividade. Não estão no núcleo criativo, mas são responsáveis pelo apoio e funcionamento da Economia Criativa. Englobam-se profissionais de negócios e finanças, advogados, médicos e profissionais da saúde, dentre outros. Nesses setores da economia, a criatividade é elemento fundamental para solução de problemas complexos, em curto espaço de tempo, com alta capacidade de discernimento e julgamento. Também são dotados de alto nível de instrução acadêmica, empírica e/ou pragmática. 
A classe criativa é composta, em sua maior parte, por engenheiros, músicos, arquitetos, cientistas da computação dentre outros. Os membros criativos de uma organização se diferem dos demais funcionários (economia formal/tradicional) pela questão do que lhes é confiado. Os integrantes criativos são remunerados para criar e inovar, gerar novos produtos, ideias, pensamentos, conhecimento, patentes, direitos autorais e serviços inovadores.

Os prestadores de serviços e a classe trabalhadora (economia formal/tradicional) são remunerados para executarem tarefas, processos, trabalhos rotineiros e de fácil substituição; logo, são menos imbuídos do produto final e possuem pouco impacto na qualidade e notoriedade. Neste ponto, os agentes criativos, ao contrário dos demais, são autores e, por vezes, detentores de direitos ou reconhecimentos, o que os faz ter uma melhor remuneração, se comparados às classes trabalhadoras (FIRJAN, 2016).

É oportuno salientar que nem sempre os profissionais criativos se apropriam do processo criativo, o que ocorre nas artes, na música ou em outras atividades que lidam diretamente com o produto final. Ao contrário, existem atividades criativas em que se observa apenas um arranjo industrial criativo ou se pode chamar de indústria da criatividade, que nada mais é que colaboradores que trabalham em partes do processo de elaboração do produto final. Estes não são atingidos, tal como se relata na literatura de Economia Criativa, dos ganhos sociais e pessoais observados em outras atividades.

Existem também aqueles cuja atividade é informal, pouco reconhecida, em pequena escala, e que também não recebem a devida atenção da sociedade nem do poder público. Mesmo que pertençam à classe criativa, não aparecem nos números oficiais de agências e governos, mas acabam por ficar à margem de estudos e análises acadêmicas. Políticas públicas poderiam trazer soluções nesta questão, com integração da esfera governamental e privada, universidades e empresas.

A classe criativa que se pode conhecer, devidamente empregada e registrada, reconhecida e detentora de bens intangíveis, possui papel econômico vital e ainda é de população inferior à classe de serviços tradicionais. Florida (2011) expõe que:

Embora a classe criativa ainda seja menor do que a classe de serviços, seu papel econômico vital a torna mais influente. Além disso, ela é significativamente maior do que a classe de "homens organizacionais", descrita por William Whyte em seu livro de 1956. Assim como a classe empresarial de Whyte, que "determinou o espírito americano" nos anos 1950, a classe criativa é a classe normativa desta era. Seus princípios, porém, são muito diferentes: individualidade, liberdade de expressão e abertura à diferença são privilegiadas em detrimento de homogeneidade, conformismo e adequação, que definiram a era organizacional (FLORIDA, 2011, p. 9).

O conceito de Indústria Cultural deve ser destacado de forma significativa à Economia Criativa, tomado pela pesquisa. Pioneiramente cunhado pela escola de Frankfurt, reflete que o consumo em massa de bens e produtos muitas vezes é formatado pela Indústria Cultural, baseado no mundo moderno, burguês, que determina o que os indivíduos devem consumir. Adorno e Horkheimer (1985), expoentes da Escola de Frankfurt, em sua obra clássica Dialética do Esclarecimento: Fragmentos Filosóficos, criticam a Indústria Cultural como uma ferramenta do capitalismo moderno, pois impede as pessoas de formarem suas próprias escolhas 
conscientes e, por isso, se tornam incapazes de escolher em suas individualidades, desejos e vontades. Ao contrário, se acomodam e perdem até mesmo o ímpeto de se aventurar e desbravar o novo ou até mesmo de apreciar a arte ou expressões artísticas.

A relação economia e criatividade é baseada no fato de que sem a criatividade a economia não poderia elevar os padrões de vida da sociedade como um todo. Segundo Romer (1986), os avanços no padrão de vida, de pessoas, famílias, empresas e Estados somente são observados com uso da criatividade. As vantagens competitivas são alcançadas quando as receitas são aperfeiçoadas, e não apenas quando se cozinha mais e mais.

Segundo Reis (2011), nas últimas décadas tem surgido uma série de termos ligados à questão do conceito da criatividade. Dentre eles a Economia Criativa, indústria criativa, classe criativa e cidade criativa. Mas o ponto é por que a criatividade é tão relevante, uma vez que já faz parte do imaginário humano há bastante tempo? Várias foram às invenções criativas do homem ao longo dos séculos, mas tem-se considerado primordial criar ambientes, ou espaços, criativos, cidades criativas, empresas criativas nos últimos anos. 0 ambiente e a cidade criativa se destacam, pois, especialmente, tendo-se em vista a limitação da Industrialização como forma de Desenvolvimento Econômico (VIEIRA, 2009).

O paradigma da economia é a escassez. Cidades, países, famílias, indivíduos e empresas possuem recursos escassos para necessidades ilimitadas. Logo, a escolha entre um bem exclui diretamente a escolha por outro. A Economia Criativa tem como principal insumo a criatividade, que é um recurso inesgotável. Por definição, criatividade cresce à medida que é utilizada Howkins (2001), e descreve ainda a quebra de paradigma:

Economia é convencionalmente definida como um sistema para a produção, troca e consumo de bens e serviços. As ciências econômicas geralmente lidam com o problema de como os indivíduos e as sociedades satisfazem suas necessidades (que são infinitas) com os recursos (que são finitos). Trata-se, portanto, basicamente da alocação de recursos escassos. Embora use ambos os termos segundo estes sentidos, mostram que as ideias não são limitadas da mesma forma que os bens tangíveis, e a natureza de sua economia é diversa (HOWKINS, 2001, p. 13).

A discussão Economia Criativa e criatividade, portanto, se dá na identificação e investigação do fenômeno criativo e como mapeá-lo, à medida que cresce em todo o mundo, em regiões e esferas tão diversas e únicas. A inovação é uma capacidade criativa significativa e pode determinar vantagens competitivas. Em diversos setores, segue a definição, a inovação perpassa todos os setores da economia, seja das indústrias automobilísticas, da moda ou da TICs. Os indivíduos e empresas que conseguem criar e dar continuidade ao processo colhem frutos duradouros de sucesso (FLORIDA, 2011).

O estado da arte da Economia Criativa traz ainda a discussão acerca das Indústrias Criativas, que têm sido motivo de amplo confronto de definições. Cabe ressaltar as variadas correntes e atualizá-las conforme o debate, ainda distante de solidificação.

O surgimento do termo "indústrias criativas" está associado a movimentos ocorridos a partir dos anos 1990 em alguns países industrializados. Mudanças econômicas e sociais fizeram com que se deslocasse o foco das atividades industriais para as atividades intensivas em conhecimento, localizadas no setor de serviços. O conceito surgiu inicialmente na Austrália, no 
início década de 1990, porém foi na Inglaterra que ele ganhou maior impulso. O caso inglês é comumente usado como referência, devido ao seu pioneirismo e à associação do tema com uma agenda política e econômica. A Inglaterra realizou um mapeamento detalhado das atividades criativas no país (DCMS, 2005) e conta com um Ministério das Indústrias Criativas (BENDASSOLI et al., 2009, p. 1).

Para Miguez (2007), as expressões indústria e Economia Criativa são novas e estão ligadas à terceira revolução industrial, à sociedade pós-industrial, pós-fordista, na qual o conhecimento e a informação são ainda recentes e discutidos amplamente. O autor argumenta que "Na linguagem da academia, pode ser dito, então, que indústrias criativas e Economia Criativa configuram um campo de conhecimento pré-paradigmático, ainda que em rota ascendente e ritmo crescente de constituição".

Howkins (2001) descreve a importância das patentes, da propriedade intelectual e dos direitos autorais. Define, pois, Economia Criativa como uma mistura de elementos: criatividade, propriedade intelectual, administração, capital e riqueza. Existem quatro formas de propriedade intelectual das quais as mais comuns são: Direitos autorais, patentes, marcas e desenhos industriais. Juntos esses quatro grandes setores constituem os setores criativos e a Economia Criativa. Esta definição é controversa. Embora todas as definições até então estejam de acordo com a prática internacional, não existe consenso em relação a esta última. A maioria dos países concordaria em dizer que a criatividade e seus setores abarcam a imaginação criativa em todas as suas formas. Porém, alguns, entre os quais a Grã-Bretanha e a Austrália, restringem o termo "setores criativos" às artes e aos segmentos culturais, excluindo os setores de ciências e patentes (HOWKINS, 2001, p. 13).

A Economia Criativa consiste, portanto, na visão pioneira de Howkins (2001, p. 13), em transações de produtos e serviços criativos. E, em cada transação, "valores são complementares, seja como propriedade intelectual intangível, valor de suporte ou plataforma física”. Logo, ao nos depararmos com um mundo globalizado e dinâmico, que passa por variadas transformações nas economias dos países, no comércio internacional e nos processos de produção de bens e serviços criativos, a propriedade intelectual toma uma proporção e importância singular.

Para Howkins (2011), as patentes são vistas como uma questão central, pois a Economia Criativa necessita de um sistema de controle de propriedade intelectual. Muitas nações, e também a ONU, possuem legislações específicas sobre as patentes e o direito autoral. A exemplo tem-se no Brasil a aprovação da Lei no 9.610 de 1998, conhecida como a lei dos Direitos Autorais, com objetivo de proteger autores e a utilização de suas obras. O amparo legal destes é fundamental ao crescimento do comércio internacional de bens e serviços intangíveis.

Embora algumas discussões sobre o tema não mencionem ou nem sequer aceitem os direitos autorais e patentes, esta pesquisa seguirá a linha teórica de Howkins (2001) e adotada pelo Departamento de Cultura, Mídia e Esportes (DCMS, 2005) no Reino Unido, onde estes são o cerne da produção de bens e serviços criativos, ligados à propriedade intelectual. Neste sentido, a moeda criativa, característica da Economia Criativa, são os direitos autorais e as patentes. A linha teórica seguida levou em conta que direitos e patentes são, sim, Economia Criativa, uma vez que garantem aos produtores e profissionais criativos, bem como às empresas ou cidades 
que a produzem, a capacidade de apropriação dos benefícios dos bens criativos. A escolha feita se dá por alinhamento com o próprio objeto de estudo, o Grupo Canção Nova, que possui um departamento de registro de marcas e direitos autorais, que será objeto de análises nos resultados.

\section{Método}

A metodologia de pesquisa teve o intuito de relacionar: dados de fontes documentais do Grupo, dados do município dos institutos de pesquisa e relatos das entrevistas individuais em profundidade, a fim de descrever o objeto de pesquisa. A problematização, de forma crítica, se construiu a fim de elucidar possíveis relacionamentos na produção de produtos e/ou serviços criativos do Grupo. Foram considerados apenas os segmentos que estão diretamente ou parcialmente ligados à Economia Criativa e ao processo inovador.

A abordagem da pesquisa foi descritiva, uma vez que foram levantados dados sobre o objeto de pesquisa, com intuito de analisar as iniciativas de Economia Criativa dentro do Grupo Canção Nova. As fases da pesquisa foram executadas em quatro etapas principais, conforme Quadro 1.

\section{Quadro 1 - Etapas da Pesquisa e Métodos Empregados}

\begin{tabular}{|l|l|}
\hline \multicolumn{1}{|c|}{ Etapas da Pesquisa } & \multicolumn{1}{c|}{ Métodos Empregados } \\
\hline $\begin{array}{l}\text { 1. Análise conceitual e } \\
\text { explicitação metodológica. }\end{array}$ & $\begin{array}{l}\text { Pesquisa e análise bibliográfica; Problematização da pesquisa; } \\
\text { Definição dos objetivos primários e secundários; Formatação e } \\
\text { conclusão da metodologia. }\end{array}$ \\
\hline $\begin{array}{l}\text { 2. Pesquisa qualitativa } \\
\text { (descritiva) }\end{array}$ & $\begin{array}{l}\text { Problematização do caso; Confecção de roteiro de entrevista; } \\
\text { Submissão ao Conselho de Ética; Coleta de dados primários por meio } \\
\text { de entrevistas Individuais em profundidade; Coleta de dados } \\
\text { secundários por meio da consulta aos gestores, profissionais criativos, } \\
\text { relatórios, documentos, dados qualitativos da FIRJAN. }\end{array}$ \\
\hline $\begin{array}{l}\text { 3. Análise e interpretação } \\
\text { dos resultados }\end{array}$ & $\begin{array}{l}\text { Escuta de gravações; transcrição de dados qualitativos; análise e } \\
\text { interpretação dos dados coletados. }\end{array}$ \\
\hline 4. Considerações Finais & $\begin{array}{l}\text { Atendimento aos objetivos de pesquisa, discussão final sobre } \\
\text { contribuições dos dados analisados e exposição de novos campos para } \\
\text { futuras pesquisas. }\end{array}$ \\
\hline
\end{tabular}

Fonte: Elaborado pelos autores (2018).

A coleta de dados primários e secundários foi realizada em 2018, após aprovação da pesquisa em Comitê de Ética em pesquisa. 


\section{Resultados e discussão}

O município de Cachoeira Paulista pertence à Região Metropolitana do Vale do Paraíba (RMVP) e tem na fé e na religiosidade um fator relevante em sua história e de seu desenvolvimento econômico.

Acredita-se que o crescimento urbano que Cachoeira Paulista sofreu nos últimos 20 anos tenha sido sob influência direta da Fundação João Paulo II, popularmente conhecida como Comunidade Canção Nova, visto que esta se localiza na porção nordeste da cidade. Desta forma, todo o crescimento no espaço urbano cachoeirense nesta direção é por consequência direta das ações da Fundação João Paulo II. A abertura de novos loteamentos no tecido urbano localizado na margem esquerda do Rio Paraíba do Sul, sobretudo em decorrência da implantação da Avenida Marginal do Rio Paraíba, também contribuiu para o aumento da área urbana no município (FERREIRA; SANCHES, 2010).

Dadas às diversas transformações observadas no município, com instalação do Grupo, ao longo dos últimos anos é notório observar o território como um espaço dinâmico (DALLABRIDA, 2011). Os movimentos de pessoas, bem como suas culturas, acabam por moldar o espaço urbano ao longo das décadas, e até mesmo dos séculos. A instalação e crescimento da Canção Nova, de certo ponto, dinamizou e transformou o território do município. Em especial, pela instalação de inúmeras pousadas, hotéis, crescimento do comércio local a partir da migração de pessoas, turistas e imigrantes, que foram analisados em seguida.

Outro estudo acerca do impacto econômico do Grupo foi realizado no âmbito do turismo religioso, do chamado Circuito Turístico Religioso, que engloba as cidades de Aparecida, Guaratinguetá, Canas e Cachoeira Paulista como centros de desenvolvimento econômico graças a atrações de fé oferecidas (MORENO, 2015). Para Moreno (2015), Cachoeira Paulista tem-se destacado no âmbito do turismo religioso, uma vez que "[...] é também destaque, sede da Comunidade Canção Nova, onde são realizados Missas especiais, retiros e acampamentos, e, no final de 2014, foi inaugurado o Santuário do Pai das Misericórdias, com capacidade para 10 mil pessoas".

\footnotetext{
Partindo da premissa de que a Canção Nova é a empresa motriz, ou seja, aquela que gera a produção local, observou-se o surgimento de diversas empresas na cidade de Cachoeira Paulista para suprir as necessidades dos seus fiéis e dos nativos. Assim, milhares de fiéis sem ter onde comer, onde dormir, entre outros aspectos negativos, gerou o surgimento de empresas que suprissem tais necessidades, tais como: padarias, hotéis, supermercados, cooperativas, etc (CANUTO, 2017, p. 145).
}

Ao observar os dados de emprego e renda do município, segundo o Ministério do Trabalho e Emprego (MTE), disponibilizados no CAGED (Cadastro Geral de Empregos e Demissões), demostra-se um ciclo de crescimento entre os anos de 2007 e 2012 (Tabela 1). O auge de admissões se deu no ano de 2010, ano marcado pelo grande crescimento do Brasil, cujo PIB cresceu 7,5\%. Observa-se ainda no município uma variação absoluta negativa nos anos de 2015 e 2016, anos em que o Brasil mergulhou em uma de suas crises econômicas mais graves. 
Tabela 1 - Emprego em Cachoeira Paulista/SP

\begin{tabular}{l|c|c|c|c|c|c|c|c|c|c}
\hline $\begin{array}{l}\text { Movimentação } \\
\text { agregada }\end{array}$ & $\mathbf{2 0 0 7}$ & $\mathbf{2 0 0 8}$ & $\mathbf{2 0 0 9}$ & $\mathbf{2 0 1 0}$ & $\mathbf{2 0 1 1}$ & $\mathbf{2 0 1 2}$ & $\mathbf{2 0 1 3}$ & $\mathbf{2 0 1 4}$ & $\mathbf{2 0 1 5}$ & $\mathbf{2 0 1 6}$ \\
\hline Admissões & 44 & 1.314 & 1.473 & 1.750 & 1.641 & 1.696 & 1.630 & 1.600 & 1.188 & 950 \\
\hline Desligamentos & 98 & 1.093 & 1.292 & 1.370 & 1.337 & 1.572 & 1.450 & 1.541 & 1.331 & 1.213 \\
\hline Variação Absoluta & -54 & 221 & 181 & 380 & 304 & 124 & 180 & 59 & -143 & -263 \\
\hline
\end{tabular}

Fonte: SEADE/CAGED (2016).

Na Tabela 2, verifica-se o total de profissionais criativos do município. Os segmentos predominantes e significativos são: Publicidade, Arquitetura, Design, Moda, Expressões Culturais, Patrimônio e Artes, Música, Artes Cênicas, Áudio e Visuais. No ano de 2014 ocorre o auge de 220 profissionais criativos. No ano de 2015, ressalta-se uma diminuição, até mesmo como reflexo da crise econômica observada, tal como nos profissionais de todos os setores. No entanto, a queda não é tão acentuada, uma vez que profissionais criativos possuem uma estabilidade maior, se comparados com outras categorias de profissionais (REIS, 2011; HOWKINS, 2001; FLORIDA, 2011).

Tabela 2 - Total de Profissionais Criativos em Cachoeira Paulista/SP

\begin{tabular}{l|l|c|c|c|c|c|c|c}
\hline & Segmento & 2004 & 2010 & 2011 & 2012 & 2013 & 2014 & 2015 \\
\hline 1 & Publicidade & 0 & 11 & 12 & 16 & 24 & 35 & 32 \\
\hline 2 & Arquitetura & 10 & 14 & 12 & 13 & 13 & 14 & 16 \\
\hline 3 & Design & 6 & 36 & 40 & 32 & 33 & 36 & 32 \\
\hline 4 & Moda & 0 & 1 & 1 & 0 & 0 & 2 & 1 \\
\hline 5 & Expressões Culturais & 5 & 5 & 2 & 3 & 3 & 5 & 4 \\
\hline 6 & Patrimônio e Artes & 5 & 3 & 3 & 5 & 6 & 7 & 5 \\
\hline 7 & Música & 5 & 14 & 18 & 16 & 18 & 16 & 20 \\
\hline 8 & Artes Cênicas & 3 & 5 & 5 & 6 & 4 & 0 & 0 \\
\hline 9 & Áudio e Visuais & 68 & 52 & 57 & 58 & 60 & 56 & 53 \\
\hline 10 & Editorial & 10 & 31 & 35 & 31 & 35 & 41 & 39 \\
\hline 11 & TIC & 8 & 11 & 8 & 7 & 10 & 8 & 8 \\
\hline 12 & P\&D & 4 & 4 & 4 & 8 & 6 & 6 & 6 \\
\hline 13 & Biotecnologia & 2 & 1 & 1 & 1 & 2 & 3 & 1 \\
\hline & TOTAL & 120 & 183 & 193 & 187 & 206 & 220 & 210 \\
\hline
\end{tabular}

Fonte: FIRJAN (2016).

O levantamento da FIRJAN, embora seja vastamente utilizado como referência em mapeamento de Economia Criativa, pode ser visto como limitado em alguns aspectos. Em primeiro lugar, por não contemplar todas as atividades relacionadas à Economia Criativa, bem como as atividades de apoio. $\mathrm{O}$ segundo ponto é o fato de o mapeamento não ter uma estimativa quanto aos empregos informais do município. Dado o caráter muitas vezes inovador e ainda pouco entendido pelas autoridades governamentais, muitos profissionais e inciativas criativas permanecem na informalidade. 
Quanto ao Grupo Canção Nova, em sua maior parte é composto por trabalhadores formais, registrados, que podem ser verificados por estudos. Contudo, existem indivíduos chamados voluntários, que contribuem com os setores criativos do Grupo, mas que não possuem vínculo formal e, por isso, não são alcançados no mapeamento da FIRJAN.

Diante da exposição do histórico da fé, religiosidade e do desenvolvimento econômico observado em Cachoeira Paulista na sua história recente e suas atuais condições de emprego, e presença da Economia Criativa, é chegado o momento de contextualizar o Grupo Canção Nova como organização criativa, fundada em 1978 pelo Padre Salesiano Jonas Abib, na cidade de Queluz/SP, com objetivo de difundir a fé católica. A aquisição da chamada Rádio Bandeirantes de Cachoeira Paulista, em 1980, levou o Grupo a ter alcance expandido. Em paralelo à entrada nos meios de comunicação, o Grupo realizava encontros e eventos religiosos (ABIB, 2012). No final dos anos 1980, uma nova etapa é observada: dá-se início às atividades televisivas, com reserva de espaços em canais pagos. $O$ alcance e público atingido tornam-se nacionais.

Do ponto de vista do Desenvolvimento Regional, a proximidade com Aparecida, de tradição centenária de romaria religiosa, favorece a interconexão e o fortalecimento do ambiente criativo. O ponto de toque na discussão, no entanto, se dá no surgimento de organizações de Economia Criativa de grande porte, em cidades pequenas do interior e com tradicionalismo e religiosidade. O que se espera como ponto de ebulição de ambientes e cidades criativas é justamente o oposto, como a pluralidade cultural, boemia, grandes centros urbanos cosmopolitas (FLORIDA, 2011). A exemplo, a cidade de São Francisco na Califórnia, com seu notório Vale do Silício tecnológico e mundialmente conhecido, assim como Paris, Londres e outras cidades criativas discutidas.

Segundo o censo do IBGE (2010) do município, há 6.221 pessoas ocupadas. Conforme esboçado na Figura 5, 17\% deste total, ou seja, 1.029 pessoas, representam apenas os funcionários do Grupo Canção Nova. O número se mostra importante, pois a população total do município é de cerca de 30 mil habitantes, segundo dados do Censo do IBGE (2010).

Ao todo foram analisados treze segmentos da economia criativa, de forma a favorecer o mapeamento da Economia Criativa em contraste com os dados apresentados pelo levantamento da FIRJAN. Como acréscimo, foi relacionado o setor de Marcas e Patentes, por se tratar de importante setor catalogador e de registro de marcas e direitos autorais de Economia Criativa no Grupo. Quanto aos setores estudados, foram selecionados cinco segmentos do Grupo Canção Nova para realização das entrevistas em profundidade: Publicidade, Marketing e Design, Editorial, Áudio e Visual, Tecnologia da Informação e Marcas e Patentes.

Os setores de Publicidade, Marketing e Design, embora sejam relacionados separadamente no Mapeamento da FIRJAN, no Grupo Canção Nova estes três segmentos encontram-se presentes no departamento de Publicidade, Marketing e Design. O setor de Audiovisuais, pertencente à grande área da Mídia (UNCTAD, 2013), contempla a Rádio e TV Canção Nova.

O segmento de Publicidade e Marketing pertence às atividades núcleo da Economia Criativa. Segundo pesquisa da FIRJAN (2016), o segmento foi um dos que apresentou o maior 
crescimento, sendo incapaz de ser comparado com base do número zero de profissionais em 2004. Com a base zero, o município passou a marca de 32 profissionais criativos.

Tabela 3 - Emprego e Renda - Publicidade

\begin{tabular}{lccc}
\hline Profissionais & $\mathbf{2 0 0 4}$ & $\mathbf{2 0 1 5}$ & Variação \\
\hline Cachoeira Paulista & 0 & 32 & $\mathbf{4}$ \\
\hline Estado de São Paulo & 11460 & 68045 & $494 \%$ \\
\hline Brasil & 22036 & 131717 & \\
\hline Remuneração & & & $\infty$ \\
\hline Cachoeira Paulista & $\mathrm{R} \$ 0$ & $\mathrm{R} \$ 2.881$ & $-26 \%$ \\
\hline Estado de São Paulo & $\mathrm{R} \$ 10.364$ & $\mathrm{R} \$ 7.679$ & $-22 \%$ \\
\hline Brasil & $\mathrm{R} \$ 8.052$ & $\mathrm{R} \$ 6.276$ & \\
\hline
\end{tabular}

Fonte: FIRJAN (2016).

Ao se verificar a Tabela 4, o setor de Marketing do Grupo Canção Nova emprega 34 profissionais criativos. O número aproxima-se do valor apresentado pela FIRJAN. É possível afirmar que existam outros profissionais criativos ligados à Publicidade e ao Marketing no município. Também é possível ressaltar que uma parcela considerável se deve aos profissionais criativos do Grupo Canção Nova.

Segundo o primeiro entrevistado do setor de Marketing do Grupo, "Todo o conteúdo criativo do Grupo Canção Nova passa pelo setor de Marketing, Publicidade e Design". Dentro deste, o entrevistado relatou as constantes reuniões criativas, chamadas de brainstorms, nas quais as ideias são debatidas livremente por toda a equipe. Relevante observar que, segundo o primeiro entrevistado, as equipes são formadas por pessoas de diferentes perfis, identidades e formações técnicas. Argumenta ainda que, para a integração desses indivíduos de pensamentos diversos, faz-se necessário o uso de ferramentas de integração constante, seja por meio de palestras, dinâmicas, cursos. O mesmo entrevistado define ainda que a equipe do setor é "bem eclética" (PRIMEIRO ENTREVISTADO, 2017). Pode-se afirmar que a caracterização do Grupo como Economia Criativa emana de alguma diversidade e com perfil agregador de equipes multifacetadas. Observa-se também que o talento individual é fator-chave e impulsionador da produção dos bens e serviços criativos (DCMS, 2005).

Sobre o processo criativo, o primeiro entrevistado (2017) expõe os processos de aprovação de novos projetos, que passam por comissões de criatividade e, em seguida, para comitês de marketing. Dentro do processo, as logomarcas, os slogans e as demais ideias são, em alguns casos, expostos em redes sociais, para interação do público do Grupo. Referente aos processos de gestão da criatividade descreve:

O impacto social e econômico do Grupo no município foi observado pelos 33 profissionais do setor (Tabela 3). Ao se tomar a remuneração média da FIRJAN de R\$ 2.881 (Tabela 7), chegase ao total de $\mathrm{R} \$ 1,2$ milhão no ano de 2015, o que irá refletir no comércio local, e também na geração de renda das famílias. Quanto ao salário médio do profissional criativo do segmento, encontrou-se acima da média do município. Enquanto em Cachoeira Paulista o salário médio dos empregos formais é de $R \$ 2.081,50$, o rendimento, segundo dados da FIRJAN, dos trabalhadores de Economia Criativa do segmento Publicidade e Marketing foi de R\$ 2.881, um valor 38\% 
superior, o que pode confirmar o debate sobre Economia Criativa como um fator de impacto econômico e social (IBGE, 2015).

A arquitetura é relacionada como Economia Criativa, pois tem sua origem no talento individual, na perspicácia e criatividade dos profissionais (BRITISH COUNCIL, 2010). O segmento de arquitetura no município de Cachoeira Paulista obteve um crescimento de $60 \%$ ao longo dos anos de 2004 a 2015 (FIRJAN, 2016). Observa-se um índice inferior ao registrado no Estado de São Paulo, com $78 \%$ de crescimento, e $81 \%$ no Brasil.

A respeito da remuneração dos profissionais, Cachoeira Paulista observou um aumento de $96 \%$, muito superior ao visto no Estado de São Paulo, com 11\%, e no Brasil, com $23 \%$ de crescimento. A propósito da remuneração média do profissional criativo do segmento, de $\mathrm{R} \$ 6.660$, esta é $219 \%$ superior ao rendimento médio do trabalhador formal do município, de R\$ 2.081,5 (IBGE, 2015). Tal informação prevalece sobre a confirmação do debate sobre Economia Criativa, neste segmento, como gerador de ganhos sociais e econômicos aos profissionais e da cidade, uma vez que irá refletir na geração de efeitos multiplicadores na economia local e no desenvolvimento econômico e social.

Tabela 4 - Emprego e Renda - Arquitetura

\begin{tabular}{lccc}
\hline Profissionais & $\mathbf{2 0 0 4}$ & $\mathbf{2 0 1 5}$ & Variação \\
\hline Cachoeira Paulista & 10 & 16 & $60 \%$ \\
\hline Estado de São Paulo & 20.297 & 36.094 & $78 \%$ \\
\hline Brasil & 62.692 & 113.499 & $81 \%$ \\
\hline Remuneração & & & $96 \%$ \\
\hline Cachoeira Paulista & $\mathrm{R} \$ 3.405$ & $\mathrm{R} \$ 6.660$ & $11 \%$ \\
\hline Estado de São Paulo & $\mathrm{R} \$ 6.984$ & $\mathrm{R} \$ 7.782$ & $23 \%$ \\
\hline Brasil & $\mathrm{R} \$ 6.305$ & $\mathrm{R} \$ 7.736$ & \\
\hline
\end{tabular}

Fonte: FIRJAN (2016).

O entendimento dos dados da FIRJAN (Tabela 5) se faz mediante comparação dos números fornecidos pelo Grupo Canção Nova, que emprega 118 profissionais no setor de engenharia e arquitetura. Entende-se, pois, que o grupo não é composto unicamente com profissionais criativos, mas toda a mão de obra ligada à construção civil, e uma parcela de arquitetos (2), e engenheiros (4).

Conclui-se que, embora o Grupo Canção Nova possua um montante expressivo de profissionais registrados neste setor (118), a grande parcela é de profissionais não ligados à criatividade, mas aos serviços da construção civil diretamente (pedreiros, etc.).

Os dados do segmento Design, segundo a FIRJAN (2015), conforme Tabela 6, demostram um crescimento expressivo de $433 \%$ no município, muito superior aos índices de crescimento do Estado de São Paulo e do Brasil como um todo. As entrevistas com o primeiro entrevistado do Marketing, nas quais se estabelece o setor de Design do Grupo Canção Nova e os dados de funcionários dos setores, demostram que (Tabela 4) 33 funcionários compõem o quadro atual. O número expressa, de alguma forma, certa proximidade com os atuais 32 profissionais do município. A remuneração média do segmento de Design, $\mathrm{R} \$ 3.006$ (Tabela 9) é 44\% superior ao 
valor do salário médio do trabalhador formal, $\mathrm{R} \$ 2.081,50$ (IBGE, 2010), o que demostra um benefício considerável a mão de obra criativa em relação as demais categorias.

Tabela 5 - Emprego e Renda - Design

\begin{tabular}{lccc}
\hline Profissionais & $\mathbf{2 0 0 4}$ & $\mathbf{2 0 1 5}$ & Variação \\
\hline Cachoeira Paulista & 6 & 32 & $433 \%$ \\
\hline Estado de São Paulo & 18.667 & 31.896 & $71 \%$ \\
\hline Brasil & 42.585 & 81.863 & $92 \%$ \\
\hline Remuneração & & & \\
\hline Cachoeira Paulista & $\mathrm{R} \$ 1.185$ & $\mathrm{R} \$ 3.006$ & $154 \%$ \\
\hline Estado de São Paulo & $\mathrm{R} \$ 3.720$ & $\mathrm{R} \$ 3.590$ & $-3 \%$ \\
Brasil & $\mathrm{R} \$ 3.010$ & $\mathrm{R} \$ 3.010$ & $0 \%$ \\
\hline
\end{tabular}

Fonte: FIRJAN (2016).

O setor de Marketing do Grupo Canção Nova emprega 33 profissionais, além de quatro estagiários e um aprendiz. Como os dados do Grupo são do ano de 2017, estes se aproximam do número relatado no ano de 2015 pela FIRJAN, no qual 32 profissionais criativos são relacionados. Tal aderência pode ressaltar o impacto do Grupo no desenvolvimento regional do município, uma vez que a Economia Criativa traz impactos relevantes nos municípios onde se apresenta especialmente na geração de emprego, renda, inclusão social e engajamento com a população local (VIEIRA; SANTOS; CARNIELLO, 2016).

O segmento de design, segundo dados do CAGED, empregava 6 profissionais criativos em 2004, conforme Tabela 15, passou para 32 no ano de 2015. Um crescimento acentuado e que pode ser impactado pelo setor de marketing do Grupo Canção Nova. Segundo o primeiro entrevistado do setor de Marketing do Grupo, o conteúdo criativo perpassa diversas atividades, tais como: cards para redes sociais, diagramação de livros, relatórios públicos de atividades, design de revistas dos sócios benfeitores, com tiragem de 350.000 exemplares mensais. Os profissionais criativos são movidos por motivação, impulso criativo, o que pode ser visto no relato da superintendente, que afirma: "Os profissionais criativos são muito antenados no mercado, e no nosso setor temos muita motivação com palestras e momentos de brainstorms".

Durante a primeira entrevista, pode-se observar que todos os setores do Grupo realizam trabalhos de comunicação e marketing junto a este setor. Desta forma, o setor de Marketing do grupo é um centralizador do conteúdo criativo institucional do grupo, com equipes de redatores, produtores, designers, câmeras men, diretor de arte, editores de vídeo e profissionais de publicidade e propaganda.

Quanto aos perfis de profissionais do grupo, dentro do setor de design foi observado que existem diversos tipos: de um lado profissionais criativos que são casados e bem ligados à família, e, de outro, profissionais solteiros, que gostam de escalar montanhas e viajar bastante (PRIMEIRO ENTREVISTADO, 2017). Logo, diversas personalidades são reunidas e tenta-se chegar a ideias inovadoras. O que perfaz um setor de Economia Criativa são justamente equipes compostas de indivíduos criativos, que representam vantagem competitiva e cujos objetivos e 
motivações são mais por motivos internos e pessoais do que apenas por contexto político e econômico.

\section{Considerações finais}

A pesquisa teve por objetivo analisar como surgiu e se organiza a Economia Criativa no Grupo Canção Nova, em suas ações, atividades, produtos, serviços e profissionais criativos no município de Cachoeira Paulista. Pode-se afirmar que o Grupo optou por um modelo de gestão de Economia Criativa e fez uso da geração de produtos e serviços um aliado para alcance de milhares de pessoas, o que caracteriza, até certo ponto, uma lógica de Indústria Criativa de massa. Pela geração de produtos (CDs, DVDs, etc), serviços (programas de TV e Rádio), tecnologias e softwares, e por meio de eventos religiosos e atividades turísticas relevantes.

Os dados do mapeamento da FIRJAN (2016) em Cachoeira Paulista demostraram um crescimento nos segmentos de música, publicidade, tecnologia da informação, design, nos âmbitos do número de profissionais criativos e de remuneração média. Os dados foram comparados entre os anos de 2004 e 2015, e entre o município de Cachoeira Paulista, o Estado de São Paulo e o Brasil. Dados que podem relacionar o município e o Grupo Canção Nova, que desenvolve ações de Economia Criativa de grande porte. Os dados da Economia Criativa, tanto do município, quanto do Grupo, foram analisados e, a sua medida, parcialmente, relacionados ao crescimento de ambos.

Os dados de segmentos não ligados às atividades do Grupo Canção Nova não apresentaram crescimento expressivo ou relevante, no entanto; levou-se em consideração a informalidade muito presente em organizações de Economia Criativa de pequeno porte e profissionais criativos. Com exceção do segmento de audiovisuais, que, embora esteja entre as atividades do grupo, mostrou decrescimento no período, ao contrário do revelado no Estado de São Paulo e no Brasil. A conclusão que se pode chegar é que a crise econômica observada no ano de 2015 foi capaz de influenciar os resultados.

Os dados qualitativos obtidos nas entrevistas em profundidade reforçam a caracterização e como se organiza a Economia Criativa no Grupo. O contraponto se dá que alguns setores não apresentam grandes invenções criativas, mas apenas uma lógica encontrada em outras organizações ao fazer uso de um modelo de gestão de Economia Criativa.

A Economia Criativa se mostrou presente em setores do Grupo Canção Nova e nos segmentos criativos em Cachoeira Paulista, a saber: produtos, serviços, processos, seleção, treinamento e recrutamento de mão de obra criativa, quantidade, qualificação e renda dos profissionais criativos.

Ao se analisarem os segmentos criativos do Grupo dentro das atividades núcleo, atividades relacionadas e atividades de apoio, a fim de entender o surgimento da Economia Criativa em um ambiente diverso do encontrado na literatura, obtiveram-se sinais consistentes característicos de organização criativa. Por outro lado, ao analisar as falas dos entrevistados, foi delineado que até certo ponto não se encontrou uma diversidade esperada. Todavia, ressaltou- 
se que a organização possui pessoas de perfis diferenciados, crenças e estilos de vida multifacetados.

Com respeito à classe criativa do Grupo, também foram observados setores que uma parcela dos que participam da Economia Criativa (segmentos Editorial, Arquitetura, Audiovisual), na pessoa dos profissionais não se apropriam do conteúdo criativo. Logo, a remuneração média se mostrou inferior ao emprego formal do município ou se equiparou a outras atividades não criativas. Conclui-se, conquanto, que a Economia Criativa é uma chave para o desenvolvimento, mas não representa uma alternativa mágica, pois apresenta também lacunas e deficiências.

O surgimento da Economia Criativa no município se deu por diversos fatores sociais, históricos e estratégicos (proximidade com Aparecida, por exemplo), dentre outros. No entanto, evidenciou-se que não foi a existência de uma classe criativa pré-existente no local, ou o fato de se encontrar em cidade pequena, e não multicultural, com características tradicionais e religiosidade católica que fez surgir a Economia Criativa, e com ela o desenvolvimento regional, local, social e econômico por consequência. A leitura se faz pela intervenção de um investimento privado, embora o Grupo Canção Nova seja uma Fundação, por meio de uma Indústria Criativa de massa. Conclui-se, portanto, que houve um investimento não público somado a fatores religiosos presentes e pré-existentes, que resultou na formação da indústria criativa, que se adequa, no entanto, à lógica da indústria cultural que caracteriza o modelo produtivo dominante contemporâneo. No caso estudado, a Economia Criativa não se apresenta como uma ruptura ou contraponto da lógica produtiva contemporânea, mas sim a usa como vetor de desenvolvimento.

A consideração relevante da pesquisa é que a Economia Criativa por meio do Grupo gerou atividade econômica, mas também não pode ser lida como única fonte de geração desta.

\section{Referências}

ABIB, M. .J. Canção Nova uma obra de deus. (Canção Nova ed.). São Paulo, 2012.

ADORNO, T; HORKHEIMER, M. Dialética Do Esclarecimento: Fragmentos Filosóficos. 2 ed. Tradução Guido Antônio de Almeida. Rio de Janeiro: Zahar 1985.

BENDASSOLLI, Pedro F. et al. Indústrias criativas: definição, limites e possibilidades. Revista de Administração de Empresas, n. 49, v.1, p. 10-18, 2009.

BRITISH COUNCIL (United Kingdom). A economia criativa: um guia introdutório. Londres: British Council, 2010.

CANUTO, R.A. A influência da expansão da comunidade católica Canção Nova no desenvolvimento de Cachoeira Paulista/SP e seus reflexos nos âmbitos social e econômico. São Paulo. Tese de Doutorado. Pontifícia Universidade Católica de São Paulo.2017. Disponível em: <https://sapientia.pucsp.br/handle/handle/20230>. Acesso em: 2 de fevereiro de 2018.

CARVALHAL, F.; MUZZIO, H.. Economia criativa e liderança criativa: uma associação (im)possível? REAd. Rev. eletrôn. adm.(Porto Alegre),[online]. 2015, vol. 21, n. 3, pp. 659-688.

DALLABRIDA, V. .R. Economia, Cultura E Desenvolvimento: Uma Primeira Aproximação Sobre As Origens Teóricas Da Abordagem Do Tema. Revista Brasileira de Gestão e Desenvolvimento 
Regional, n. 12, v. 2, p. 282-299, 2011. Retrieved 20 february, 2019, from <http://www.rbgdr.net/revista/index.php/rbgdr/article/view/432/249>.

DCMS (Department for Culture, Media and Sport). Gov.uk. Creative Industries Mapping Documents. 1998. [Online]. [20 February 2019]. Available from:

https://www.gov.uk/government/publications/creative-industries-mapping-documents-1998.

FERREIRA, M. A. G; SANCHES, F.O. Análise do processo de crescimento urbano da cidade de Cachoeira Paulista (SP) de 1985-2007 utilizando técnicas de sensoriamento remoto. Porto Alegre: Anais do XVI Encontro Nacional dos Geógrafos, 2010. Acessado em 20 fevereiro 2019. Disponível em: http://www.conhecer.org.br/enciclop/2010b/analise\%20do\%20processo.pdf

FIRJAN. Mapeamento da indústria criativa no Brasil. SESI/SENAI, Rio de Janeiro, 2016. Acessado em 20 fevereiro 2019. Disponível em: https://www.firjan.com.br/economiacriativa

FLORIDA, R. A ascensão da Classe Criativa. Porto Alegre: Ed. L\&PM, 2011.

FUNDAÇÃO JOÃO PAULO II. Relatório de atividades de 2015, 2016. Cachoeira Paulista. Fundação João Paulo II.

FUNDAÇÃO JOÃO PAULO II. Balanço patrimonial e demonstrações contábeis de 2015, 2016. Cachoeira Paulista.

HARVEY, D. A condição pós-moderna: uma pesquisa sobre as origens da mudança cultural. São Paulo: Loyola, 1993.

HOWKINS, J. The Creative Economy. How people make money from ideas London: Penguin Press, 2001.

HOWKINS, J. A Economia Criativa. Como Ganhar Dinheiro com Ideias Criativas. London: Penguin Press., 2011.

IBGE - Instituto Brasileiro de Geografia e Estatística (2010). Pesquisa Nacional por Amostra de Domicílios: síntese de indicadores 2010. Rio de Janeiro: IBGE. Acessado em 20 fevereiro 2019. Disponível em:

https://ww2.ibge.gov.br/home/estatistica/indicadores/trabalhoerendimento/pnad_continua/d efault.shtm

LEITÃO, C. Criatividade e diversidade cultural brasileira como recursos para um novo desenvolvimento. In: Plano da Secretaria da Economia Criativa: políticas, diretrizes e ações, 2011-2014. Ministério da Cultura (Org.). Brasília: Ministério da Cultura, 2011.

MORENO, P. A. C. (2015) Turismo religioso católico no brasil: perspectivas e desafios de um crescente setor econômico. Juiz de Fora: Anais Do XIV Simpósio Nacional da ABHR. Acessado em 20 fevereiro 2019. Disponível em:

http://www.abhr.org.br/plura/ojs/index.php/anais/article/view/920

MIGUEZ, P. Economia Criativa: uma discussão preliminar. In: NUSSBAUMER, Gisele Marchiori (Org.). Teorias e políticas da cultura: visões multidisciplinares. Salvador: EDUFBA. Coleção CULT, 1., 2007, p.96-97. 
MUZZIO, H.; PAIVA JÚNIOR, F. G.. A Gestão na Economia Criativa e a Identidade do Indivíduo Criativo Inovador: Em Busca de uma Convergência. In: Encontro da ANPAD, 38, 2014, Rio de Janeiro, RJ. Anais... Rio de Janeiro, 2014.

ONU, UNCTAD. Creative Economy Report 2010- Creative Economy: A Feasible Development Option. UN. 2010. Acessado em 20 fevereiro 2019. Disponível em:

https://unctad.org/en/docs/ditctab20103_en.pdf

ONU, UNCTAD Creative Economy Report 2013-Creative Economy: A Feasible Development Option. UM. 2013. Acessado em 20 fevereiro 2019. Disponível em:

http://www.unesco.org/culture/pdf/creative-economy-report-2013.pdf

PIRES, Vladimir Sibylla,; ALBAGLI, Sarita. Estratégias empresariais, dinâmicas informacionais e identidade de marca na economia criativa. Perspectivas em Ciência da Informação, 17(2), 2012. , p.109-122. https://dx.doi.org/10.1590/S1413-99362012000200008

ROMER, P. . Increasing returns and long run growth. The Journal of Political Economy, Chicago, v. 94, n. 5, 1986, p. 1002-1037. Acessado em 20 fevereiro 2019. Disponível em:

http://citeseerx.ist.psu.edu/viewdoc/download?doi=10.1.1.589.3348\&rep=rep1\&type=pdf

REIS, A. C. F. . Transformando a criatividade brasileira em recurso econômico. In: economia criativa como estratégia de desenvolvimento: uma visão dos países em desenvolvimento. Itaú Cultural, 2008. pp. 126-143.

REIS, A. C. F. Cidades Criativas, burilando um conceito em formação. São Paulo, lara Revista de Moda, Cultura e Arte.v. 4 n 1, 2011. Acessado em 20 fevereiro 2019. Disponível em:

http://www1.sp.senac.br/hotsites/blogs/revistaiara/wp-

content/uploads/2015/01/12_IARA_vol4_n1_Reflexoes.pdf

SANTOS, E.L et al. Desenvolvimento: um conceito multidimensional. DRD, n. 1, ano 2. , 2012. Acessado em 20 fevereiro 2019. Disponível em:

http://recipp.ipp.pt/bitstream/10400.22/1858/1/ART_ElinaldoSantos_2012.pdf

VIEIRA, E. T.; SANTOS F. R.; CARNIELLO, M. F.. Economia criativa e o desenvolvimento no município de Taubaté-SP. Revista Brasileira de Gestão e Desenvolvimento Regional. Taubaté, v. 12, n. 2, 2016. P. 161-184. Acessado em 20 fevereiro 2019. Disponível em:

<http://www.rbgdr.net/revista/index.php/rbgdr/article/view/2317>.

VIEIRA, E.T.. Industrialização e políticas de desenvolvimento regional: o Vale do Paraíba paulista na segunda metade do século XX. Tese de Doutorado em História Econômica. USP, 2009. 